\title{
A ONTOLOGIA SOCIAL "FRACA" EM HABERMAS: O DÉFICIT NORMATIVO DO MUNDO DA VIDA (LEBENSWELT)
}

\author{
Social Ontology "weak" by Habermas: the normative deficit of the life world (Lebenswelt)
}

\author{
José Henrique Sousa Assai*
}

\begin{abstract}
Resumo: Habermas não faz uma teoria ontológica em seus escritos, mas, por outro lado, não abandona por completo o substrato ôntico ao tematizar em sua teoria da sociedade o mundo da vida. Mesmo não fazendo uma ontologia em seu caráter mais restrito, Habermas trata a respeito do ser do mundo na sociedade - o que nos permite pensar uma abordagem ontológica social - a partir de uma triádica articulação conceitual, a saber: personalidade, sociedade e cultura. Tal concepção está vinculada à teoria da sociedade do próprio Habermas.

Pretendo demonstrar que o conceito de mundo da vida (Lebenswelt) que Habermas utiliza para categorizar sua teoria da sociedade compreendida por mundo da vida e sistema possui um forte caráter não-normativo, mas, sim apenas fenomênico. Na verdade, o que se coloca como fundamento do conceito de mundo da vida habermasiano é uma ontologia fraca entendida aqui enquanto um saber que não remete a uma normatividade, cuja tarefa é endereçada à Teoria Crítica na qual o próprio Habermas é herdeiro e, por isso mesmo, essa noção enfraquecida do mundo da vida não faz jus à Teoria Crítica que tem em seu arcabouço conceitual uma forte noção normativa da sociedade conhecida pela égide de ontologia social.
\end{abstract}

Palavras-chave: Ontologia social. Mundo da vida. Teoria da sociedade.

\begin{abstract}
Habermas doesn't make an ontological theory in his writings, but on the other hand, doesn't give up altogether the ontic substrate to establish themes in his theory of society the world of life. Even without using ontology in its more restricted character, Habermas tries about the world of being in society - whose theory allows us to think an ontological social approach - from a triadic conceptual articulation, namely, personality, society and culture. Such conception is linked to the theory of Habermas's own society (life world and system).

I intend to demonstrate that the concept of life world (Lebenswelt) that Habermas uses to categorize his theory of society comprised of lifeworld and system has a strong nonnormative, but rather just phenomenal. Indeed, what stands as the foundation of Habermas' concept of world life is a weak ontology understood here as a knowledge that doesn't refer to a normative, whose task is addressed to critical theory in which Habermas himself is an heir and therefore even this weakened notion of lifeworld unflattering to Critical Theory which takes its conceptual framework of a strong normative concept known by social ontology society.
\end{abstract}

Keywords: Social Ontology. Life-World. Theory of society.

\footnotetext{
* Doutorando em Filosofia pela Pontifícia Universidade Católica do Rio Grande do Sul (PUCRS). Contato: jhsassai@ufma.br
}

\begin{tabular}{|c|c|l|l|l|l|}
\hline intuitio & $\begin{array}{c}\text { ISSN } \\
1983-4012\end{array}$ & Porto Alegre & Vol.7- $\mathrm{N}^{\mathrm{o}} .1$ & $\begin{array}{c}\text { Junho } \\
2014\end{array}$ & p.215-225 \\
\hline
\end{tabular}


Habermas não tem em sua vasta produção intelectual uma teoria ontológica propriamente dita, mas pode-se afirmar que mesmo sem possuir uma teoria do ser enquanto ser, o herdeiro mais antigo da Teoria Crítica lança mão de alguns pressupostos ontológicos ${ }^{1}$ - ao se reportar ao "enquanto ser" em um mundo objetivo, social e (inter) subjetivo - para postular parte da sua teoria da sociedade que está ligada a uma normatividade que visa os processos de emancipação dos problemas sociais, ou seja, tais pressupostos estão justamente no conceito de uma parte de sua teoria da sociedade que é o mundo da vida; a outra parte diz respeito ao sistema. Ambas as noções encontram-se presentes na Teoria do Agir Comunicativo, doravante, na versão alemã, TKH ${ }^{2}$.

É possível, portanto, sustentar tal afirmação anterior? Creio que sim, se tomarmos por referência o conceito habermasiano de mundo da vida concebido desde a sua obra magna (TKH). Por motivos óbvios, já que aqui se trata de um artigo, não é o intento maior exaurir o desenvolvimento conceitual de mundo da vida na vasta obra literária habermasiana, porém pode-se salientar, ainda que em linhas gerais, o sentido fundante da referida estrutura ôntica - mundo da vida - e seu estatuto puramente fenomênico não-normativo; pois, em primeiro lugar, se uma Teoria Crítica postula a tese de uma teoria da sociedade normativa e, na concepção de Habermas, a teoria da sociedade é formada basicamente pelo mundo da vida e pelo sistema; então, em segundo, a normatividade aqui deveria ser entendida como um dever-ser já presente na própria estrutura formal e conteudal de mundo da vida contida na teoria da sociedade. Nesse sentido, o conceito de mundo da vida deveria trazer consigo no hic et nunc já uma orientação normativa e, não como aponta Habermas, apenas uma ideia fenomênica vinculada à tradição semântico-linguística de uma comunidade orientada ao entendimento mútuo.

Diante do exposto, minha argumentação orienta-se primeiramente em apresentar o conceito de mundo da vida e sua (s) estrutura (s) [1]- estão contidas nessas estruturas algumas tentativas de Habermas em "adjetivar" o mundo da vida que, a meu ver, não passam de uma forma de remediar à socapa uma normatividade que poderia ser intrínseca a ela - para que em seguida que perante o desenvolvimento conceitual do mundo da vida é possível repensar o Lebenswelt não como elemento apenas distinto na teoria da sociedade "pré-teórico" (vor theoretisch), porém, sobretudo, enquanto pressuposto de mediação ontológica social da normatividade. Assim, é preciso rediscutir também a tarefa do mundo da vida enquanto "Raum symbolisch" e pensá-la fundamentalmente como "Raum der

\footnotetext{
${ }^{1}$ As recentes pesquisas do prof. Eduardo Luft servem-me como fonte de aprofundamento para rediscutir o próprio pressuposto filosófico habermasiano de mundo da vida que tem pressupostos ontológicos de caráter social. Nesse sentido, saliento dois artigos do prof. Eduardo Luft sobre ontologia deflacionária que, mesmo sendo em outro contexto filosófico, permite repensar numa perspectiva de uma crítica interna problemas filosóficos de grande envergadura, tais como: liberdade x contingência e criticidade x sistematicidade. Cf. LUFT, Eduardo. Ontologia deflacionária e ética objetiva: em busca dos pressupostos ontológicos da teoria do reconhecimento, Veritas, Porto Alegre, v. 55, n. 1, 2010, p. 82 - 120. Cf. também: LUFT, Eduardo. Holismus und deflationäre Ontologie. In: EIDAM, Heinz, HERMENAU, Frank, SOUZA, Draiton (org.). Metaphysik und Hermeneutik: Festschrift für Hans Georg Flickinger zum 60. Geburtstag. Kassel: Kassel Uni Press, 2004. 425 p. (Klasseler Philosophische Schriften 38).

${ }^{2}$ HABERMAS, Jürgen. Theorie des Kommunikativen Handelns: Zur Kritik der funktionalistischen Vernunft. 1. ed. Frankfurt am Main: Suhrkamp Verlag. 1995. 640 p.
}

\begin{tabular}{|c|c|l|l|l|l|}
\hline intuitio & $\begin{array}{c}\text { ISSN } \\
1983-4012\end{array}$ & Porto Alegre & Vol.7 $-\mathrm{N}^{\mathrm{o}} .1$ & $\begin{array}{c}\text { Junho } \\
2014\end{array}$ & p.215-225 \\
\hline
\end{tabular}


normative Gründe", ou seja, a ideia de mundo da vida passa de um puro espaço simbólico a um espaço que é fonte de normatividade, pois uma teoria da ação social ainda orienta-se por um dever-ser que incialmente encontra-se no próprio Lebenswelt [2].

\section{Mundo da vida e sua estrutura ontológica}

Sabe-se que Habermas "lançou mão" inicialmente do conceito fenomenológico husserliano de mundo da vida para apresentar como parte de sua teoria da sociedade ${ }^{3}$. Só que diferente de Husserl, Habermas relacionou ao mundo da vida à noção do agir comunicativo, ou como é mais conhecido o conceito de razão comunicativa, ao estabelecer, primeiramente, que "wie die Lebenswelt als der Horizont, in dem sich die kommunikativ Handelnden "immer schon" bewegen [...] Er bildet einen komplementärbegriff zum Kommunikativen Handeln" " ${ }^{4}$. Nesse sentido, o mundo da vida não é apenas uma noção interna ao conceito de agir comunicativo, mas, sobretudo, é conceito complementar do mesmo. Não é demais observar que o Lebenswelt possui em sua estrutura lógica, por assim dizer, um telos de um idealismo intersubjetivo no qual a razão mesma é pensada mediante uma intersubjetividade na qual só se reconhece enquanto racionalidade pelo fato de que tenha um telos do entendimento mútuo como fim último de seu agir. Poder-se-ia interpor aqui se Habermas, em última instância, teria nessa conceptualização uma noção metafísica de razão apesar de que o mesmo se autointitule um pós-metafísico ${ }^{5}$; mas, esse não é o escopo do nosso trabalho aqui e, sim, demonstrar que a ideia de mundo da vida já deveria conter nela mesma uma normatividade que lhe falta por se autointitular enquanto elemento importante na teoria da sociedade habermasiana que, por sua vez, possui um telos normativo.

O pressuposto ontológico do mundo da vida, tal como Habermas afirma na TKH, reside nos três tipos de mundo que se vinculam à ideia da relação entre ator e mundo (objetivo):

Mundo objetivo (como a totalidade das entidades que são possíveis as afirmações verdadeiras);

Mundo social (como a totalidade legítima das relações interpessoais regulamentadas);

\footnotetext{
${ }^{3}$ SCHUTZ, Alfred, LUCKMANN, Thomas. The Structures of the Life-World. Evanston: Northwestern Press, 1973. 335 p. cf. HABERMAS, 1995, p. 182 - 198. Em um texto mais recente, Habermas afirma que a sua posição no que diz respeito ao conceito de mundo da vida, comparando-o ao de Husserl, foi que este último orientou-se pelo paradigma da consciência, mas ele o faz tendo como enfoque o telos da relação comunicativa. HABERMAS, Jürgen. Von den Weltbildern zur Lebenswelt. p.23. In: Nachmetaphysisches Denken II: Aufsätze und Repliken. Berlin: Suhrkamp, 2012. 334 p.

${ }^{4}$ HABERMAS, Jürgen. Das Konzept der Lebenswelt und der hermeneutische Idealismus der verstehenden Sozio logie. In:__. Theorie des Kommunikativen Handelns: Zur Kritik der funktionalistischen Vernunft. 1. ed. Frankfurt am Main: Suhrkamp Verlag. 1995. p. $182-228$.

${ }^{5}$ HABERMAS, Jürgen. Pensamento pós-metafísico. Tradução de Flávio Beno Siebeneichler. Rio de Janeiro: Tempo Brasileiro, 1990. 271 p.
}

\begin{tabular}{|c|c|c|c|c|c|}
\hline intuitio & $\begin{array}{c}\text { ISSN } \\
1983-4012\end{array}$ & Porto Alegre & Vol.7- $\mathrm{N}^{\mathrm{o}} .1$ & $\begin{array}{c}\text { Junho } \\
2014\end{array}$ & p.215-225 \\
\hline
\end{tabular}


Mundo subjetivo (como a totalidade das vivências que o falante pode expressar verdadeiramente diante um público) ${ }^{6}$.

A partir dessa pequena taxonomia ontológica e levando em consideração o telos do entendimento mútuo, Habermas infere que o mundo da vida se faz presente na perspectiva real dos indivíduos em sociedade configurando em outros três componentes estruturais (strukturellen Komponenten): cultura (Kultur), sociedade (Gesellschaft) e Personalidade (Persönlichkeit). A cultura é entendida enquanto armazém do saber (Wissensvorrat), onde os participantes da comunicação tratam de se entender sobre algo no mundo; a sociedade diz respeito às ordens legítimas que, por um lado, asseguram a solidariedade dos participantes do agir comunicativo e, por outro, regem suas pertenças aos grupos sociais; por fim, a personalidade, as competências que fazem de um sujeito com capacidade de falar e agir participar do processo do entendimento e, assim, afirmar sua própria identidade $^{7}$. De fato, essa construção conceitual sofreu pequenas glosas - sobretudo no que diz respeito à racionalidade no mundo da vida ${ }^{8}$, mas, na sua centralidade, não sofreu modificações que levassem a outra forma de conceber o mundo da vida. Diante desse quadro nocional, Habermas aborda dois grandes pressupostos ontológicos que, a rigor e sinteticamente, eu os resumiria em: forma e conteúdo. Quanto ao primeiro, entendo aquilo que eu cognominei de "taxonomia do mundo da vida"; quanto ao segundo, os elementos internos, os componentes integrantes, desse mesmo mundo da vida. Só que nessa esteira, ainda vejo a forte conotação fenomenológica - nem um pouco normativa arraigada de "forma suspeita" a Husserl, porém Habermas insiste em afirmar que o mundo da vida se reproduz materialmente e que nessa reprodução estruturada simbólico-semanticamente é preciso levar em consideração duas dimensões: o espaço social (soziale Raum) e a época histórica (historische Zeit $)^{9}$. A meu ver, vincular o espaço societário e a historicidade ao mundo da vida é de alguma maneira atribuir contornos "adjetivos" de normatividade para uma construção conceitual e predominantemente fenomênica, descritiva, e que, por sua vez, denota, a meu ver, um fraco escopo normativo e por isso mesmo remete a uma noção de uma ontologia social enfraquecida de normatividade ${ }^{10}$. Vejamos a seguir essa descritividade.

Habermas utilizou como base os trabalhos de Mead e Durkheim para desenvolver sua teoria da sociedade. Assim, o mundo da vida tem processo de racionalização e, portanto, diferencia-se

\footnotetext{
${ }^{6}$ HABERMAS, 1995 , p. $183-184$.

${ }^{7}$ HABERMAS, 1995, p. 209.

${ }^{8}$ HABERMAS, Jürgen. Verdade e Justificação: estudos filosóficos. Tradução de Milton Mota. São Paulo: loyola, 2004. 330 p.

${ }^{9}$ HABERMAS, 1995, p. 209.

${ }^{10}$ A suspeita de um déficit da Teoria Crítica não é novidade para os próprios participantes dela, pois há algum tempo que Axel Honneth indagou, numa perspectiva da crítica interna à Teoria Crítica sob o ponto de vista filosófico, se o conceito de teórico-linguístico de entendimento comunicativo não seria um meio categorial de remediar o déficit normativo da Teoria Crítica. Naquela ocasião, Habermas aceitou que seria sim a resposta, pois o que está em jogo, em última instância, delineia-se em três formas: o conceito de razão, o conceito de verdade e a teoria da democracia. Conferir esse debate na íntegra em: HABERMAS, Jürgen. Dialetik der Rationalisierung: Defizite der Kritische Theorie. In:___ Die Neue Unübersichtlichkeit: Kleine Politische Schriften V. Frankfurt am Main: Suhrkamp Verlag, 1985. p. 167 - 208.
}

\begin{tabular}{|c|c|l|l|l|l|}
\hline intuitio & $\begin{array}{c}\text { ISSN } \\
1983-4012\end{array}$ & Porto Alegre & Vol.7 $-\mathrm{N}^{\mathrm{o}} .1$ & $\begin{array}{c}\text { Junho } \\
2014\end{array}$ & p.215-225 \\
\hline
\end{tabular}


estruturalmente em três níveis: diferenciação estrutural do próprio mundo da vida; diferenciação de forma (Form) e conteúdo (Inhalt) e, por fim, diferenciação das reproduções simbólicas. O que nos interessa aqui são apenas as duas primeiras formulações.

Ao tratar da diferenciação no mundo da vida, Habermas apresenta três momentos relacionais: cultura e sociedade; personalidade e sociedade; cultura e personalidade ${ }^{11}$. Quanto à primeira diferenciação, diz respeito ao "crescente acoplamento dos sistemas institucionais das concepções de mundo" (zunehmenden Entkoppelung des Institutionensystems von den Weltbildern); a segunda trata do "alargamento do espaço de contingência para a produção de relações interpessoais" (Erweiterung des Kontingenzspielraums für die Herstellung interpersonaler Beziehungen) e, por fim, a terceira tematiza "a renovação das Tradiçõe ${ }^{12}$ que dependeria da disposição crítica e capacidade de inovação dos indivíduos" (Erneuerung von Traditionen immer stärker von der Kritikbereitschaft und Innovationsfähigkeit der Individuen abhängig wird). No interior dessa diferenciação, haveria uma condição de corolário específico de cada um dos elementos do mundo da vida e, assim, para a cultura ter-se-ia um estado de contínua revisão da Tradição, para a sociedade uma situação de independência das ordens legítimas de procedimentos formais para a fundamentação de normas e, por fim, à personalidade caberia o estabelecimento autodirigido do "eu" enquanto identidade. Diante dessa arquitetônica construtiva, parece que Habermas interpõe, sim, notas ontológicas de cunho social na sua teoria da sociedade ou, como afirmei, Habermas faz ainda que tacitamente uma ontologia social. Ela pode não ser elaborada com o rigor epistêmico ou propriamente dialético-ontológico que os críticos poderiam exigir, porém há nessa diferenciação uma abordagem social ontológica precisamente quando Habermas afirma a existência de uma realidade objetiva e contingencial que se expande a partir de um "eu" entendido racional-comunicativamente. A questão crítica que permanece, em minha investigação, é que essa mesma ancoragem não permite pensar ainda em uma ontologia normativa, isto é, uma abordagem capaz de prover no mundo da vida o elemento normativo que oriente a um movimento de dever-ser perante os problemas sociais. Uma teoria da sociedade, assim como os seus elementos integrantes - no caso aqui o mundo da vida -, não pode olvidar em se constituir em toda a sua plenitude, em ser normativa. O mundo da vida deveria conter em seu conjunto categorial elementos de normatividade, portanto, de uma ontologia social "forte" e não "fraca", isto é, que contenha já em sua gênese um déficit normativo.

Por outro lado, a diferenciação da forma e conteúdo do mundo da vida estabelece-se em três níveis: cultural, social e da personalidade ${ }^{13}$. À primeira, correspondem os conteúdos concretos já entrelaçados nas imagens de mundo míticas e mitigados precisamente nos pressupostos da

\footnotetext{
${ }^{11}$ HABERMAS, 1995, p. 219 - 220.

12 Por Tradição, Habermas entende que, perante o contexto histórico, é a ação de prosseguirmos aproblematicamente algo que outros ("antepassados") iniciaram e fizeram antes do "nós" (da atual vivência). Cf. HABERMAS, Jürgen. Identidad Nacional e Identidad Postnacional. In: postnacionales. 2. ed. Madrid: Tecnos, 2002. p.111 - 121.

${ }^{13}$ HABERMAS, 1995, p. 220. . Identidades nacionales $y$
}

\begin{tabular}{|c|c|c|c|c|c|}
\hline intuitio & $\begin{array}{c}\text { ISSN } \\
1983-4012\end{array}$ & Porto Alegre & Vol.7 $-\mathrm{N}^{\circ} .1$ & $\begin{array}{c}\text { Junho } \\
2014\end{array}$ & p.215-225 \\
\hline
\end{tabular}


argumentação, nos procedimentos da argumentação e nos valores fundamentais abstratos; no nível da sociedade os princípios gerais são cristalizados e se impõem na sociedade moderna os princípios do ordenamento jurídico e da moral; por fim, no nível da personalidade os processos de socialização são solvidos mediante as estruturas cognitivas. Mais uma vez essa diferenciação não logra êxito no tocante ao estabelecer já no conceito de mundo da vida e suas estruturas uma normatividade, uma ontologia social que traga consigo o gérmen denotativo de um dever-ser, isto é, como Habermas afirma, em outra passagem, não se coloca a questão das patologias do mundo da vida ${ }^{14}$ (Pathologien der Lebenswelt). Habermas só aborda tal patologia a partir do entendimento de que existe um processo de cooptação do sistema (poder e dinheiro) ao mundo da vida, porém ele, apesar de afirmar que existam deformidades no mundo da vida ou processos de colonização do mundo da vida, parte sempre de um dualismo - de cunho intersubjetivo - e que, em última instância, o conceito de mundo da vida possui estruturas ineludíveis de uma razão que se autocompreende teleológica e substancialmente estruturada posto que o mundo da vida parecesse sempre querer ser "engolido" pelo sistema. Daí parece não haver espaço nessa articulação dualista intersubjetiva em Habermas, sob o ponto de vista da noção de mundo da vida, que se permita pensar em um componente estruturante normativo do Lebenswelt.

No capítulo da TKH intitulado Marx und die These der inneren Kolonialisierung, o conceito de mundo da vida parece ganhar um status mais próximo da normatividade postulada pela Teoria Crítica. Ao falar especificamente sobre o Estado social, onde articulam-se, por um lado, as esferas da ação da economia e da política e, por outro, as estruturas comunicativas e da esfera pública ${ }^{15}$, Habermas parece orientar a sua atenção para uma concepção social ontológica do mundo da vida ao vinculá-la à esfera pública (política), no sentido de que a própria esfera pública advém desse mundo da vida - que não é político - e que, portanto, sugeriria uma noção normativa; porém, pelo fato de que o mundo da vida não é político e, por isso mesmo, Habermas aloca sua força de pesquisa no espaço público - esse, sim, torna-se político - é que se pode reafirmar o déficit normativo do conteúdo ontológico do mundo da vida. Nesse caso, Habermas estava discorrendo acerca do estágio do capitalismo tardio na sociedade. Apenas nesse contexto, é que mais precisamente o mundo da vida foi vinculado à esfera pública política, ocasionando, inclusive, outra variante do mundo da vida: a força dos grupos sociais presentes nele. A questão se coloca no seguinte sentido: por que é preciso adjetivar o mundo da vida como "grupo social que tem força" se o mesmo já tivesse contido uma denotação normativa? Talvez fosse mais "simples" interpor na tríade - personalidade, cultura e sociedade componentes de um dever-ser, porém Habermas insiste baseá-las por meio do conceito de razão comunicativa e só a partir da racionalidade ao entendimento mútuo arrolar uma teoria da sociedade. $\mathrm{O}$ mundo da vida, portanto, estaria encapsulado nessa "conceituologia" racional comunicativa de Habermas e isso, no meu entendimento, não permite pensar e nem desenvolver uma ontologia social normativa. Mais uma vez, o déficit de normatividade estaria posto na teoria habermasiana.

${ }^{14}$ HABERMAS, 1995, p. 566.

${ }^{15}$ HABERMAS, 1995, p. 512.

\begin{tabular}{|c|c|l|l|l|l|}
\hline intuitio & $\begin{array}{c}\text { ISSN } \\
1983-4012\end{array}$ & Porto Alegre & Vol.7 $-\mathrm{N}^{\mathrm{o}} .1$ & $\begin{array}{c}\text { Junho } \\
2014\end{array}$ & p.215-225 \\
\hline
\end{tabular}


A proposta em atrelar o mundo da vida à teoria da sociedade que se vê envolta pela racionalidade comunicativa ganhou novos contornos em Kommunikatives Handeln und detranszendentalisierte Vernunft ${ }^{16}$. Nesse texto, Habermas repõe à noção da razão comunicativa frente às recensões de Thomas McCarthy, no tocante a ideia de razão em Kant, a fim de que o próprio conceito de razão seja entendido numa transição que parte da ideia de uma razão "pura" a uma razão "situada". Por razão "situada" - e mais uma vez o uso de adjetivos para o conceito de razão Habermas entende "uma destranscendentalização do sujeito cognoscente [...]. O sujeito finito deve se encontrar 'no mundo' sem perder sua espontaneidade 'produzida no mundo' (welterzeugende)" ${ }^{17}$. A destrancendentalização da razão entendida comunicativamente e que estabelece vínculo social ontológico com o mundo da vida é, assim, definida por Habermas: "a destranscendentalização orienta-se, por um lado, à colocação dos sujeitos socializados nos contextos dos mundos da vida e, por outro, ao cruzamento da cognição com o falar e o agir" 18 .

A partir dessa exposição conceitual acerca da razão destranscendentalizada, parece-me que Habermas se dá conta que o mundo da vida traz consigo um pressuposto ontológico social de caráter que eu denomino "forte", no sentido de que se assim não o fosse eu não veria o porquê de Habermas carregar o conceito de mundo da vida de adjetivos que postulem uma normatividade. Além do cruzamento da cognição com o falar e o agir, essa presencialidade dos sujeitos que estão imersos numa socialidade contextual parece orientar uma leitura acerca do mundo da vida como um conceito ainda incompleto em sua estrutura perante a teoria da sociedade habermasiana. As reiteradas tentativas de reconstituir o mundo da vida no modelo de uma razão destranscendentalizada fazem com que Habermas oriente a sua pesquisa no sentido de um mundo da vida "presêntico" (präsenten Lebenswelt), isto é, parece que não haveria necessidade de apresentar uma abordagem do mundo da vida de forma hodierna, interpondo também uma ontologia social, se o próprio entendimento do Lebenswelt não tivesse problemas demarcatórios sob o ponto de vista da própria filosofia social habermasiana. A suspeita de Honneth há anos - conforme descrito nos Kleine Politische Schriften $V-$ reitera-se, recentemente, quando Honneth relê a TKH no tocante à glosa, dada por Habermas, de mundo vida perante os processos contínuos de colonização (do sistema): para Honneth, ocorre a colonização do mundo da vida social ${ }^{19}$. Mundo da vida social? Aqui, a meu ver, a tese crítica, de Honneth, é pertinente, pois o argumento do ex-assistente de Habermas é que tal formulação pressuporia uma constituição normativa que concederia a autorrealização bem sucedida de todos os

${ }^{16}$ HABERMAS, Jürgen. Kommunikatives Handeln und detranszendentalisierte Vernunft. Stuttgart: Reclam, 2001.87 p.

${ }^{17}$ HABERMAS, 2001, p. 9.

${ }^{18}$ Na versão original: Die Detranszendentalisierung führt einerseits zur Einbettung der vergesellschafteten Subjekte in lebensweltliche Kontexte, anderseits zur Verschänkung der Kognition mit Sprechen und Handeln. Zusammen mit der Theoriearchitektonik verändert sich der Begriff der 'Welt'. Tradução nossa. Cf. HABERMAS, 2001, p. 16.

${ }^{19}$ HONNETH, Axel. Pathologien der Vernunft: Geschichte und Gegenwart der Kritischen Theorie. 1. ed. Frankfurt am Main: Suhrkamp, 2007. 239 p.

\begin{tabular}{|c|c|l|l|l|l|}
\hline intuitio & $\begin{array}{c}\text { ISSN } \\
1983-4012\end{array}$ & Porto Alegre & Vol.7 $-\mathrm{N}^{\mathrm{o}} .1$ & $\begin{array}{c}\text { Junho } \\
2014\end{array}$ & p.215-225 \\
\hline
\end{tabular}


membros da sociedade; porém, concordando com Honneth, creio que a especificidade de tal terminologia ainda não está suficientemente clara, pois nesse caso apenas foi apontada uma diferença entre discurso filosófico moral de injustiça social. Em suma, a forma terminológica habermasiana revela expressões que consistem na diferença entre patologia social e racionalidade "mancante" (mangelnden Rationalität), no sentido de que falta algo nessa racionalidade ${ }^{20}$. O que falta, de fato, é explicitar e desenvolver uma concepção de razão social onde o mundo da vida faça parte desse entendimento de maneira não meramente formal, porém normativa, isto é, que o mundo da vida não seja entendido apenas como estrutura simbólica de fundamentações corporificadas ${ }^{21}$, mas como base normativa que denote um sentido "forte" de uma ontologia social que se constitua em uma mediação normativa na sociedade. Não obstante, no entendimento habermasiano, parece que uma possibilidade em que haja essa fundamentação corporificada do mundo da vida é vincular a razão social - que traz consigo o mundo da vida - com a esfera pública política (Öffentlichkeit). O mundo da vida é visto, portanto, primeiramente como um espaço simbólico de fundamentações corporificadas; e, em segundo lugar, para pensar esse projeto Habermas junta à comunicação com os papéis pragmáticos das fundamentações (que são as exigências normativas provenientes do mundo da vida). Nesse caso, o output desses fundamentos se solidificaria tanto nas tradições culturais quanto nos procedimentos institucionais; daí o caráter do espaço simbólico e de fundamento (Raum symbolisch verkörperter Gründe). Particularmente, vejo que é nesse ponto que Habermas iniciou um projeto de filosofia social que tomasse a sério o papel do mundo da vida para além de uma "fenomenologia"; isso se deu na tentativa de atrelar as instituições - [que] "são uma parte do mundo da vida" ${ }^{22}$ (die Lebenswelt, von der Institutionen einen Bestandteil bilden [...]) - como mediações normativas. O Lebenswelt passou a ser visto na obra Direito e Democracia como "condição de integração social". A partir desse ponto, minha investigação migra para o segundo tema que eu me propus a demonstrar, a saber: o mundo vida não pode ser entendido apenas como um “espaço simbólico para fundamentações”, mas, sobretudo, como um espaço de fundamentações (Raum der Gründe).

\section{Repensando o Lebenswelt: do espaço simbólico (Raum symbolisch) para um espaço de fundamentações (Raum der Grü̈nde)}

Não é tarefa fácil repensar o mundo da vida que em seu conteúdo já tenha um quantum de normatividade. Como esse artigo ainda é um projeto inicial que me proponho a fazer, nesse sentido

\footnotetext{
${ }^{20}$ HONNETH, Axel. Eine Soziale Pathologie der Vernunft. In: . Pathologien der Vernunft: Geschichte und Gegenwart der Kritischen Theorie. 1. ed. Frankfurt am Main: Suhrkamp, 2007. 239 p.

${ }^{21}$ HABERMAS, 2012, p. 54.

${ }^{22}$ HABERMAS, Jürgen. Recht als Kategorie der gesellschaftlichen Vermittlung zwischen Faktizität und Geltung. p. 40. In:__ Fakzität und Geltung: Beiträge zur Diskurstheorie des Rechts und des demokratischen Rechsstaats. ed. ampl. Frankfurt am Main: Suhrkamp, 1994. 704 p. Há a versão em língua portuguesa. Cf. HABERMAS, Jürgen. Direito e Democracia: entre facticidade e validade. Tradução de Flávio Beno Siebeneichler. Rio de Janeiro: Tempo Brasileiro, 1997. 354 p. v. 1. À guisa de orientação, no decorrer no presente texto utilizarei a versão original simbolizando-o pelas iniciais $F G$.
}

\begin{tabular}{|c|c|l|l|l|l|}
\hline intuitio & $\begin{array}{c}\text { ISSN } \\
1983-4012\end{array}$ & Porto Alegre & Vol.7 $-\mathrm{N}^{\mathrm{o}} .1$ & $\begin{array}{c}\text { Junho } \\
2014\end{array}$ & p.215-225 \\
\hline
\end{tabular}


pretendo iniciar essa discussão filosófica sem o intuito de que a mesma venha a ser considerada como "a palavra" mais correta acerca do tema em questão.

Conforme salientei, o conceito de mundo da vida, a partir de FG, passou a ser entendido - e não só o mundo da vida, mas principalmente a esfera pública política - como algo relacionado a categorias institucionais. Não que precisamente o mundo da vida tenha sido definido, por Habermas, como institucional, mas quando ele afirma que as instituições (sociais presentes nas democracias liberais e republicanas) são parte do mundo da vida, ocorre aqui uma nova noção do conceito de Lebenswelt, pois até então Habermas não havia ainda apresentado o mundo da vida a uma ideia de institucionalidade social. Os adjetivos ao mundo da vida não são meros expletivos ou glosas na teoria da sociedade, porém, se os mesmos existem e estão continuamente sendo reforçados, é porque recai a suspeita de certa fragilidade no acoplamento entre sistema e mundo da vida na teoria da sociedade tal como Habermas a entende.

O que está em jogo, no fundo, é a suspeita, até do próprio Habermas, se o agir comunicativo não está atrelado ao mundo da vida, pois, conforme argumento, se o mesmo estiver sob a ótica da normatividade é preciso, então, repensar o Lebenswelt. Habermas expressa esse problema ${ }^{23}$ ao afirmar que, ainda sob a perspectiva da razão comunicativa, em caso de dissenso - um risco fático - que é alimentado pela contingência, isso faria da integração social através do uso da linguagem orientado ao entendimento algo muito improvável. Então, numa perspectiva crítica interna, é preciso admitir que a improbabilidade decorrente da contingência altera a própria compreensão de mundo da vida como elemento que não dá conta de uma normatividade - expressa tacitamente pelo procedimento institucional - sendo visto majoritariamente, por Habermas, como "espaço simbólico". Penso que o espaço inerente ao mundo da vida é também "espaço normativo". Outro problema, nesse argumento habermasiano, é a contingência fática: ela corrói a pretensão metafisica do telos do entendimento mútuo uma vez que o problema da criticidade e sistematicidade parecem pouco definidos aqui; porém, a minha questão repousa basicamente sobre a concepção de Lebenswelt enquanto espaço de fundamentações. A seguinte nota de rodapé, em FG, denota a dificuldade em admitir posteriormente que mundo da vida é também socialmente concebido:

O conceito básico de comércio comunicativo explica como a integração social através das forças de ligação pode consistir em uma linguagem intersubjetivamente compartilhada. Isto impõe aos sujeitos sobre os temas que querem usar as energias de ligação da linguagem, restrições pragmáticas e eles precisam sair do egocentrismo de sua orientação sucesso, a fim de cumprir os critérios públicos da racionalidade voltada ao entendimento. A partir desta perspectiva, a sociedade apresenta-se como mundo da vida simbólico estruturado que é reproduzido sobre a ação comunicativa. Claro que isso não significa que no mundo da vida não possam ocorrer interações estratégicas ${ }^{24}$.

\footnotetext{
${ }^{23}$ HABERMAS, 1994, p. 38.
}

${ }^{24} \mathrm{Na}$ versão original: Der Grundbegriff des kommunikativen Handels erklärt, wie soziale Integration über die Bindungkräfte eine intersubjektiv geteilten Sprache zustandekommen kann. Diese erlegt den Subjekten, die die

\begin{tabular}{|c|c|c|c|c|c|}
\hline intuitio & $\begin{array}{c}\text { ISSN } \\
1983-4012\end{array}$ & Porto Alegre & Vol.7 - N .1 & $\begin{array}{c}\text { Junho } \\
2014\end{array}$ & p.215-225 \\
\hline
\end{tabular}


O que Habermas situa como "interações estratégicas", eu compreendo situações históricas de normatividade, isto é, são as condições de indivíduos ou grupos sociais que, por motivações reivindicatórias para a melhoria de seus respectivos contextos sócio-históricos, reivindicam o seu direito às justificações normativas ${ }^{25}$. Nesse sentido, o mundo da vida não pode estar situado puramente em uma esfera pré-simbólica ou pré-estruturada ${ }^{26}$; ao contrário, ele deve ser compreendido como fonte das justificações e reivindicações da normatividade. Nele, já está contida uma espécie de critério público (Öffentlichen Kriterien) exigido pela racionalidade comunicativa procedimental, já que contém em seu conteúdo a personalidade, a sociedade e suas ordens legítimas e a cultura como toda forma de se conceber qualquer tipo de conhecimento (Wissensvorrat) ${ }^{27}$.

Se falarmos do mundo da vida a partir de um contexto mais abrangente do que, por exemplo, o de ser um elemento pré-simbólico, podemos tomá-lo como base de uma razão (prática) que fomenta justificação normativa (e moral) ${ }^{28}$. É, pelo menos, o que Habermas nos sugere ao qualificar o mundo da vida como 'social'; mas, se o mundo da vida passa a ser categorizado como social - reiteradamente adjetivado - é porque, a meu ver, há de se admitir que no entendimento habermasiano do conceito mesmo de mundo da vida falta algo que lhe dê sentido fundante: "no mundo da vida social de referência institucional, função e situação de ação decidem tanto sobre o tipo de ação esperada e, quando os conflitos vierem, decidem quanto sobre uma correspondente forma de comunicação a nível reflexivo" ${ }^{29}$.

Parecem que as suspeitas de Forst e Honneth, chamados da $3^{a}$ geração da Teoria Crítica (Frankfurt Schule), no que diz respeito a repensar a teoria da sociedade habermasiana, passam a ganhar força. Foi Forst quem primeiro apresentou a noção de Raum der Gründe ${ }^{30}$ e ele o fez ao tratar de onde podem ser produzidos os fundamentos da ação na sociedade inserida numa teoria da razão. Forst não afirma categoricamente que o mundo da vida seja esse espaço de fundamentações; por outro lado, é possível pensar que o mundo da vida "reivindica" tal posição normativa. E esse entendimento é viável a partir do momento em que uma teoria da ação racional e uma teoria da sociedade pressupõem,

Bindungsenergien der Sprache nutzen wollen, pragmatische Beschränkungen, auf und nötig sie, aus der Egozentrik ihrer Erfolgsorientierung herauszutreten, um sich den öffentlichen Kriterien der Verständigunsrationalität zu stellen. Aus dieser Sicht, präsentiert sich die Gesellschaft als symbolische strukturierte Lebenswelt, die sich über Kommunikatives Handeln reproduziert. Daraus folgt natürlich nicht, da $\beta$ in der Lebenswelt keine strategischen Interaktionen auftreten können”. Tradução nossa. Cf. HABERMAS, 1994, p. 43.

${ }^{25}$ FORST, Rainer. Das Recht auf Rechtfertigung: Elemente einer KonstruktivistichenTheorie der Gerechtigkeit. 1. ed. Frankfurt am Main: Suhrkamp, 2007. 413 p.

${ }^{26}$ HABERMAS, 1994, p. 56.

${ }^{27}$ HABERMAS, 1995, p. 209.

${ }^{28}$ FORST, 2007, p. $13-53$.

29 "In der sozialen Lebenswelt entscheiden institutioneller Bezug, Funktion und Handlungssituation über den zu erwartenden Handlungstypus und, wenn es konflikten kommt, über eine entsprechende kommunikationsform auf reflexiver Ebene". Tradução nossa. Cf. HABERMAS, Jürgen. Kommunikative Rationalität und grenzüberschreitende Politik: eine Replik. p. 406 - 459. In: NIESEN, Peter, HERBORTH, Benjamin. Anarchie der Kommunikativen Freiheit. Frankfurt am Main: Suhrkamp, 2007. 464 p.

${ }^{30}$ FORST, 2007, p. 24.

\begin{tabular}{|c|c|l|l|l|l|}
\hline intuitio & $\begin{array}{c}\text { ISSN } \\
1983-4012\end{array}$ & Porto Alegre & Vol.7- $\mathrm{N}^{\mathrm{o}} .1$ & $\begin{array}{c}\text { Junho } \\
2014\end{array}$ & p.215-225 \\
\hline
\end{tabular}


em última instância, um elemento fundante. Estou convencido que esse elemento pode ser o mundo da vida. Ele não deve ser entendido como uma fantasmagoria na teoria da sociedade, um elemento de caráter simbólico encapsulado na razão idealista intersubjetiva, mas como uma categoria ontológica ativa no processo normativo. Nele - no Lebenswelt - encontra-se acima de tudo a liberdade entendida fundamentalmente tanto como ética e política quanto como princípio fundante da razão ${ }^{31}$. Se for para ficarmos ainda na esteira da razão, há de pensar que o Lebenswelt tem algo de racional por justamente ter consigo a liberdade enquanto expressão da razão e, nesse sentido, o mundo da vida passa a ser repensado como ente ontológico social que emana "fortes" pretensões normativas toda vez que houver sinais e contextos patológicos da razão.

\section{Referências}

FORST, Rainer. Das Recht auf Rechtfertigung: Elemente einer KonstruktivistichenTheorie der Gerechtigkeit. 1. ed. Frankfurt am Main: Suhrkamp, 2007. 413 p.

HONNETH, Axel. Pathologien der Vernunft: Geschichte und Gegenwart der Kritischen Theorie. 1. ed. Frankfurt am Main: Suhrkamp, 2007. 239 p.

HABERMAS, Jürgen. Nachmetaphysisches Denken II: Aufsätze und Repliken. Berlin: Suhrkamp, 2012. 334 p. Verdade e Justificação: estudos filosóficos. Tradução de Milton Mota. São Paulo: loyola, 2004. 330 p. Identidades nacionales y postnacionales. 2. ed. Madrid: Tecnos, 2002. p.111 - 121.

Kommunikatives Handeln und detranszendentalisierte Vernunft. Stuttgart: Reclam, 2001. 87 p.

Theorie des Kommunikativen Handelns: Zur Kritik der funktionalistischen Vernunft. 1. ed. Frankfurt am Main: Suhrkamp Verlag. 1995. 640 p.

Fakzität und Geltung: Beiträge zur Diskurstheorie des Rechts und des demokra-tischen Rechsstaats. ed. ampl. Frankfurt am Main: Suhrkamp, 1994. 704 p.

Pensamento pós-metafísico. Tradução de Flávio Beno Siebeneichler. Rio de Janeiro: Tempo Brasileiro, 1990. $271 \mathrm{p}$.

Die Neue Unübersichtlichkeit: Kleine Politische Schriften V. Frankfurt am Main: Suhrkamp Verlag, 1985. p. $167-208$.

LUFT, Eduardo. Ontologia deflacionária e ética objetiva: em busca dos pressupostos ontológicos da teoria do reconhecimento, Veritas, Porto Alegre, v. 55, n. 1, 2010, p. 82 - 120.

LUFT, Eduardo. Holismus und deflationäre Ontologie. In: EIDAM, Heinz, HERMENAU, Frank, SOUZA, Draiton (org.). Metaphysik und Hermeneutik: Festschrift für Hans Georg Flickinger zum 60. Geburtstag. Kassel: Kassel Uni Press, 2004. 425 p. (Klasseler Philosophische Schriften 38).

NIESEN, Peter, HERBORTH, Benjamin. Anarchie der Kommunikativen Freiheit. Frankfurt am Main: Suhrkamp, 2007. 464 p.

SCHUTZ, Alfred, LUCKMANN, Thomas. The Structures of the Life-World. Evanston: Northwestern Press, $1973.335 \mathrm{p}$.

Recebido em: 06/05/2014

Aprovado para publicação em: 09/05/2014

${ }^{31}$ RÜMELIN, Julian-Nida, VOSSENKUHL, Wilhelm. Ethische und politische Freiheit. Berlin: de Gruyter, $1998.532 \mathrm{p}$.

\begin{tabular}{|l|c|l|l|l|l|}
\hline intuitio & $\begin{array}{c}\text { ISSN } \\
1983-4012\end{array}$ & Porto Alegre & Vol.7- $\mathrm{N}^{\mathrm{o}} .1$ & $\begin{array}{c}\text { Junho } \\
2014\end{array}$ & p.215-225 \\
\hline
\end{tabular}

